\title{
Derroteros de la educación peruana en el XXI: interculturalizar, decolonizar y subvertir
}

Jorge Luis Yangali Vargas a

\section{Resumen}

En el artículo nos acercamos a la concepción del enfoque intercultural en la educación. Partimos del análisis de uno de los productos más importantes producidos desde que el sistema educativo peruano asumiera el enfoque intercultural. Resultado de ello, desde un enfoque decolonial, proponemos tres caminos que se debieran seguir si queremos que dicho enfoque no sea un coto para la población indígena y más bien se constituya en un proyecto emancipador de todos los peruanos: curricularizar el saber local, repensar la interculturalidad en territorios no solo étnicos, e imponer el aprendizaje de lenguas nativas en las escuelas no interculturales.

Palabras clave: Educación. Interculturalidad. Decolonialidad. Lenguaje. Territorio.

\section{Introducción}

La presencia de la Universidad Nacional Mayor de San Marcos, a través de Instituto de Investigación Lingüística Aplicada (CILA) ${ }^{1}$ en la Amazonía peruana ha fortalecido la educación intercultural bilingüe. Las investigaciones y acciones sanmarquinas forman parte del programa de Educación Intercultural Bilingüe para la Amazonía (Eibamaz) ${ }^{2}$, que priorizó su trabajo en tres campos: formación docente, producción de materiales e investigación aplicada. La importancia del trabajo en estos tres componentes radica en comprometer a los mismos miembros de las poblaciones indígenas en la elaboración de cuadros pictóricos de su entorno y de una cosmovisión que les represente.

\footnotetext{
a Universidad Nacional del Centro del Perú. Huancayo, Perú.

1 Entre el 2007 y 2009 el Instituto de Investigación Lingüística Aplicada (CILA) de la Facultad de Letras y Ciencias Humanas de la Universidad Nacional Mayor de San Marcos desarrolló un proyecto de investigación e intervención en las comunidades indígenas amazónicas asháninka, yine y shipiba, producto del cual se han publicado tres informes de las investigaciones (las mismas que referenciamos en la bibliografía).

2 Proyecto educativo auspiciado desde la primera década de este nuevo siglo por el gobierno de Finlandia e implementado por la Unicef. Su antecesor (desde 1946) tuvo como principal protagonista al Instituto Lingüístico de Verano (ILV).
} 
Desde nuestro punto de vista, estos tres componentes son iterativos y paliativos de la condición representacional política indígena. Ninguno de ellos atenta y confronta la construcción hegemónica de lo indígena. Los tres no enrostran la realidad geopolítica, cultural y territorial de dichas comunidades amazónicas: haber sido desterritorializadas en lo geopolítico y colonizadas en lo cultural.

Lo imperativo de los trabajos de investigación sanmarquinos, motivo de nuestro comentario, es que "contribuyan al diseño e implementación de políticas públicas en el campo de la educación intercultural bilingüe" (CILA, 2012a: 11); o como lo dice tecnocráticamente María Cortez Mondragón, directora del proyecto ejecutado por el CILA, "proporcionar información sociocultural de base para el fortalecimiento de la [EIB]" (2012a: 12). En otras palabras, que sirvan, políticamente hablando, para lo mismo: contener la representación sub-versiva o por lo menos decolonial de los sujetos bajo estudio y vindicación.

Tomando en cuenta el imperativo señalado líneas arriba surge la pregunta: ¿de qué se habla cuando se alude a la educación intercultural bilingüe? En principio apoyémonos en la definición formulada por Cortez Mondragón: se trata de implementar una mejor educación, que respete la identidad, la cultura y la lengua de los pueblos amazónicos; que trace la construcción de un camino prometedor en el que dichas comunidades afirmen su identidad valorando sus ricos aportes culturales en el ordenamiento del mundo (CILA, 2012b). Esto es, a nuestro entender: un sistema educativo alterno y peligrosamente aislacionista - por efectos de la focalización que cerca su atención en la población propiamente indígena - y que no involucra a los otros agentes sociales del sistema binario: los colonos, a quienes se les excluye del programa y, al hacerlo, se les exculpa del estigma colonial con el cual se ha construido y afirmado la identidad hegemónicamente dominante del colono ${ }^{3}$.

Para no ser mezquinos con el valioso aporte del programa sanmarquino en su conjunto, habría que rescatar la pertinencia de con-ceder a la cosmovisión discursiva indígena el rango categorial de epistemología, además del involucramiento de los pobladores indígenas en la construcción de su inventario epistemológico, puesto que es a ellos a quienes se les atribuye la corresponsabilidad en la recolección de información (CILA, 2012a).

Schmidt-Welle sostiene una postura en nuestra misma perspectiva al exigir: "que la mayoría o las élites aprendan lenguas indígenas y códigos culturales de los grupos subalternos" (citado por Pozo Menares, 2014: 5). 
En otras palabras, el aporte de dicho programa, y de manera especial de los informes de investigación aplicados, fue haber otorgado a la población indígena - los actores locales delegados por las mismas comunidades indígenas - la oportunidad de manipular las tecnologías antropológicas, sociológicas y estético-culturales con las cuales ellos han construido su propia representación escénica ${ }^{4}$, performatividad discursiva que se espera sea reproducida por ellos o por los colonos - previa aprobación, en los contextos jurídicos actuales, de estos, claro está - a través del principal medio reproductor de productos epistemológica y occidentalizadamente validados: la educación.

Sobre la manipulación de tecnologías extranjeras en manos de los nativos, si la EIB formase parte de un proyecto político decolonial invasivo sería peligrosamente emancipador; sin embargo, como la participación de los actores indígenas está pautada por el libreto del programa aplicado por el CILA - en este punto la importancia del CILA no es propiamente el CILA, pues puede tratarse de cualquier otra institución administradora del programa ${ }^{5}$, la potencialidad y peligrosidad de la manipulación epistemológica occidental está controlada ${ }^{6}$.

\section{Educación Intercultural Bilingüe: una necesidad}

No cabe duda de que la educación intercultural bilingüe es una necesidad apremiante puesto que, como lo define Edgar Iglesias, "es el modelo más apropiado para la transformación social y para el reconocimiento de las distintas expresiones de la diversidad" (IGLESIAS, 2014: 168). La EIB es una necesidad en el Perú, en primer lugar porque la población peruana, cultural y lingüísticamente hablando, no es una sociedad homogénea; más bien se trata de un territorio signado por la presencia de múltiples grupos étnicos, culturales y lingüísticos. Un segundo aspecto que hace de la EIB una tarea urgente es la condición marginal de aquellas geoculturas que no responden al arquetipo lingüístico y universalizable de lo peruano: la hegemonía hispanoparlante. Marginalización que actualiza la definición mariateguista de lo estructuralmente peruano: una sociedad semicolonial, calificativo que ampliaremos más adelante y contra el cual, desde una concepción política decolonial, la EIB se erige como posible vía instrumental que conduciría el proceso decolonialista.

4 Cortez Mondragón especifica que esta concesión fue una opción intencional por parte de la Dirección del Programa y tuvo la finalidad de "incrementar las capacidades y competencias investigativas de los propios actores locales y comunales" (CILA, 2012b).

5 Por ejemplo, el Programa Alianza Perú para la Educación Rural "Ruta del Sol" Véase Aportes a la construcción... (2014).

6 Para comprender la potencialidad decolonial (de resistencia y defensa territorial) de la manipulación tecnológica por parte de las comunidades amazónicas, véanse los estudios de Varese (1973) y Regan (1993). 
Un tercer aspecto que nos invita a apostar por la EIB tiene que ver con los fatales efectos de los dos primeros: la desvalorización de los saberes epistemológicos locales, tanto por colonos que la emplean como estrategia para justificar su domino, como por los mismos nativos que así expresan la vulnerabilidad de su resistencia. Es en este tercer aspecto en el que más se ha trabajado, tanto desde el Ministerio de Educación como desde los programas como el ejecutado por CILA; esto es: la curricularización de contenidos culturales propios de aquellos pueblos resistentes a la avasallante occidentalización cultural. Acompañan al saber curricular otras competencias (oportunidades pedagógicas) que de acuerdo a Iglesias (2014) son propias de la interculturalidad:

- La oportunidad de cuestionar (lo naturalizado).

- La oportunidad de priorizar los procesos por delante de los resultados.

- La oportunidad de fortalecer la comunidad educativa.

- La oportunidad de seguir transformando socialmente.

- La oportunidad de ser facilitadores en los procesos educativos ${ }^{7 .}$

Quisiéramos, en las siguientes líneas, profundizar en estas posibilidades pedagógicas que nos proporciona el enfoque intercultural. Para ello partimos por trazar la tarea política que debiera ir de la mano del modelo intercultural: la descolonización.

\section{Para la descolonización}

Para hablar de la descolonización nos valdremos del resumen que realiza Joseff Estermann de dicha teoría política cultural:

Mientras que "colonización" es el proceso (imperialista) de ocupación y determinación externa de territorios, pueblos, economías y culturas por parte de un poder conquistador que usa medidas militares, políticas, económicas, culturales, religiosas y étnicas, "colonialismo" se refiere a la ideología concomitante que justifica y hasta legitima el orden asimétrico y hegemónico establecido por el poder colonial... La "colonialidad" representa una gran variedad de fenómenos que abarcan toda una serie de fenómenos desde lo psicológico y existencial hasta lo económico y militar, y que tienen

\footnotetext{
7 La experiencia del CILA nos muestra que el rol facilitador también se produce en el campo investigativo.
} 
una característica común: la determinación y dominación de uno por otro, de una cultura, cosmovisión, filosofía, religiosidad y un modo de vivir por otros del mismo tipo (ESTERMANN, 2014: 3).

A partir de Estermann podemos concluir que la

[...] colonialidad no es el hecho (neutral) de que todas y todos somos producto de este proceso humano de la inter-trans-culturación - que es un hecho histórico-sino que contiene un aspecto analítico y crítico que tiene que ver con la involuntariedad, dominación, alienación y asimetría de estructuras políticas, injusticia social, exclusión cultural y marginación geopolítica (2014: 3).

Este interesante discurso político puede verse desacreditado y desvirtuado, como observa Estermann ${ }^{8}$, si no hay cambios estructurales; sin embargo, las tareas políticas que traza la decolonialidad nos permiten entender lo peruano desde la definición estructural que le atribuyera Mariátegui (2007).

Premunidos de estos postulados, observemos las dos últimas décadas del siglo XX del Perú, es decir aquellos años en los que esta nación se vio sacudida por un oleaje de violencia jamás experimentado. Aunque la población peruana sufrió las guerras libradas en la búsqueda de su independencia política del dominio español, así como la funesta guerra con Chile, ambas en el siglo XIX ${ }^{9}$, ninguna de ellas es comparable con lo acontecido en las décadas finiseculares del XX: violencia político militar que rasgó uno de los velos (ŽIŽEK, 1999) con los que hasta en ese entonces se cubría la indecorosa intimidad-real peruana ${ }^{10}$ : minorías criollas o cholas (choris son llamados por los amazónicos) gobernantes y dueñas de los medios de producción y representación jurídica, política y cultural que fantaseaban con una nación homogénea (chola) cercando, para ello, a los sectores sociales más vulnerables en extensos territorios heterogéneos bajo imaginarios que José Carlos Mariátegui ${ }^{11}$ calificara en los años 20 del pasado siglo, refiriéndose a la

\footnotetext{
8 "Mientras que la matriz económica, política y social, pero sobre todo los esquemas mentales e introyectos psíquicos quedan enraizados en mentalidades y estructuras coloniales, occidentocéntricas y neo-coloniales, la tan anhelada 'descolonización' se convierte en algo de maquillaje y de folclore" (ESTERMANN, 2014: 4).

9 La Comisión de la Verdad y Reconciliación (CVR) califica estas décadas como marca de horror y deshonra, décadas de destrucción y muerte (CVR, 2003).

${ }^{10}$ Según la CVR la principal lección extraída de este periodo de violencia estructural tiene que ver con el reconocer la imposibilidad de convivir con el desprecio (CVR, 2003), es decir, con la discriminación cultural, social y económica.

${ }^{11}$ La CVR, al caracterizar a las víctimas de violencia, precisa que de cada cuatro, tres fueron campesinos y de lengua quechua. Es decir, el perfil de las víctimas es el mismo que corresponde al sector históricamente ignorado (CVR, 2003).
} 
economía y política peruana, de semifeudales y semicoloniales. Imaginarios que traslucen la imagen de un Perú escindido en dos grandes sectores sociales: uno instalado en la modernidad, y otro situado al margen, distante y esquivo a ella.

Caracterización imaginaria de la sociedad peruana que ocupó la labor reflexiva de muchos de los destacados intelectuales que tempranamente procuraron explicar el fenómeno de horror que acontecía en buena parte del vasto territorio peruano. Como la que hiciera el historiador Alberto Flores Galindo demostrando cambios sustantivos en el modo de producción semifeudal que en los iniciales años del brote subversivo, 1980 -aunque "persistía como principal sustento de un Estado burocratizado" (FLORES, 1986: 355)- había dejado de ser una realidad enteramente plausible, mas había pasado a constituirse en dogma sociológico y económico sobre lo peruano, por lo que el partido comunista Sendero Luminoso, y luego el Movimiento Revolucionario Túpac Amaru (las dos principales agrupaciones alzadas en armas), supieron capitalizar para atizar el infernal y dantesco incendio que desoló parte del territorio andino.

La descripción de la sociedad peruana como semicolonial fue el dogma político y representacional, imaginario o real, mariateguista que empleó la izquierda sublevada para sostener el levantamiento armado por más de dos décadas. Una estructura colonialista que sobrevivía tanto en instituciones religiosas (principalmente católicas), como en un Estado burocratizado y centralista que descalificaba y deslegitimizaba productos y prácticas que surgían en las periferias provincianas. De ahí que no resulta extraño que se le atribuyera a estas últimas haber sido bastiones y proveedores de cuadros o mandos, tanto de Sendero Luminoso, como del MRTA (FLORES, 1986; CVR, 2003).

Pero los calificativos de semifeudalidad y semicolonialidad no solo fueron dogmas empleados por la izquierda insurrecta, sino también por la izquierda democrática, y hasta por las instituciones gubernamentales, logrando de este modo, construir cercos (UBILLUZ et al., 2009) de demostración de poder hegemónico en el que se aglutinaron cuerpos (físicos y sociales) que se resistían a la modernidad para sacrificarlos. Estamos hablando de sacers en la dimensión que Giorgio Agamben le da a dicho término: una vida absolutamente expuesta a que se le dé muerte, objeto de una violencia que excede a la vez la esfera del derecho y del sacrificio (AGAMBEN, 2006).

El que volvamos a definir lo peruano desde la huella de lo colonial no tiene que ver con un deseo de volver renovadamente a colocarle el velo, sino de observar que después del suceso político-militar traumático, el velo no ha sido 
quitado aún; es más, si se rasgó en algún momento, este se ha vuelto a coser. La violencia finesecular del siglo XX fue capaz de rasgar el velo en dos, debilitando la estructuración de lo peruano que se sostenía en dicho imaginario. En términos de Badiou (2004), fue el acontecimiento del cual devino y se hizo evidente la verdad. No obstante, develado el rostro con tremenda cicatriz colonial, se hace urgente la construcción o emergencia de un proceso político cultural y, sobre todo, educativo que la cure. Cura que a nuestro juicio parte por arriesgar o apostar por el enfoque intercultural en tres dimensiones.

\subsection{Primera apuesta: curricularizar el saber local}

La principal virtud de la Educación Intercultural Bilingüe es la incorporación de contenidos locales o étnicos al currículo y a la práctica pedagógica; cuestionamos, no obstante, su alcance restringido a aquellas instituciones educativas creadas para tal fin. Instituciones abarrotadas por niños indigenas a quienes se les ofrecen, curricularmente, contenidos que ellos asimilan con mayor familiaridad $y$, por ende, identidad en su seno familiar ${ }^{12}$. Esto nos lleva a preguntarnos: ¿qué propósito tiene otorgar a los saberes comunales el atributo de ser contenidos enseñables, si solo lo pueden ser al interior de los centros educativos de este tipo, y para los niños en quienes dichos saberes forman parte de su formación cotidiana? En similar perspectiva, Ibáñez y su equipo multidisciplinar critican aquellos modelos bilingües interculturales en los que se cuenta con "currículos culturalmente diferenciados, y por tanto excluyentes, que encapsularían la diversidad cultural del estudiantado y no cumplen con la declaración de diálogo intercultural" (IBÁÑEZ et al., 2012: 216).

Si proyectos investigativos y culturales como los realizados por la Universidad de San Marcos nos demuestran la plausibilidad de curricularizar el saber local, nada impide que se rompan los muros del centro educativo intercultural bilingüe y la EIB forme parte de la acción educativa de los centros educativos que no tienen dicho rótulo, es decir, aquellos centros educativos a donde tarde o temprano se dirigirán los niños egresados de las escuelas EIB. En otras palabras, que la EIB llegue a donde los saberes locales aún no han alcanzado el estatuto de ser enseñables. Esto nos lleva a pensar en la impertinencia de la educación intercultural bilingüe desvinculada de un real acercamiento a la epistemología otra.

Pensar la posibilidad potencial de incorporar la epistemología otra en el currículo occidentalizado peruano implica pensar la decolonialidad de la sociedad peruana

${ }^{12}$ Fuenzalida nos recuerda que "El curriculum, como dispositivo, forma parte de un sistema político estratégico a través del cual se asegura la reproducción ideológica y simbólica de los grupos de poder" (FUENZALIDA RODRÍGUEZ, 2014: 7). 
en su conjunto; la misma que se materializaría en la incorporación de, por lo menos, el desarrollo curricular progresivo, continuo y universalizable de los saberes locales. Y, de estos, por lo menos la enseñanza de una de las lenguas originarias - la de más fluencia entre la población local circundante a los centros educativos (bilingües o monolingües). Y como no se cuenta con profesionales bilingües, se trata de quebrar otro de los pruritos de la educación e incorporar a los agentes comunales en el acto educativo. A estos agentes se les debe asegurar su progresiva profesionalización pedagógica. Tarea, esta última, en la que las universidades regionales tienen vasta experiencia.

Creemos que uno de los factores para que los saberes locales no alcancen el valor de contenido curricular universalizable y por tanto, incluible, en el currículo de educación básica regular no bilingüe, tiene que ver con la definición de educación intercultural al servició de la inclusión y encuentro con las comunidades culturales heterogéneas no hegemónicas ${ }^{13}$. Definición que podemos encontrar, por ejemplo, en Patricia Rincón, para quien la interculturalidad es "definida no solo como el encuentro entre las diferentes culturas, sino fundamentalmente como el respeto y reconocimiento entre ellas" dentro de un marco de educación y sociedad justa (RINCÓN MURCIA, 2007: 118) ${ }^{14}$. La importancia de la propuesta de Rincón está respaldada en los presupuestos teóricos de John Rawls y Hannah Arendt, pensadores que, según Rincón Murcia (2007: 119), definen el deber ser de la política no basada en el "concepto de vida buena [...] sino en el de vida justa", lo que alienta el respeto a las libertades y diferencias individuales.

Quisiera destacar la importancia de la definición de política que Rincón emplea en el campo educativo intercultural no circunscrito y restringido a las comunidades indígenas, sino en la educación de los detentadores del poder, esto es, para el caso peruano amazónico, de los colonos, a quienes se les deben enseñar lenguas y saberes de las culturas colonizadas, no porque su enseñanza sea buena, sino porque el clamor de la justicia curricular lo demanda ${ }^{15}$.

Tal punto de vista de la política educativa nos invita a proyectarla no como la llave para la seguridad y el éxito individual y, por tanto, para la homogeneización

\footnotetext{
${ }^{13}$ Ibáñez et al., hablan de la adopción, por parte de aquellos países de la región con la "evidente diferenciación étnico-cultural de sus poblaciones", de "modelos biculturizadores para mejorar la atención educativa a la diversidad" (IBÁÑEZ, 2012: 216).

14 Tomemos en consideración la metáfora que emplea José Zavala para calificar la interculturalidad: pasaporte diplomático que permite "señalar buenas intenciones" (en POZO MENARES, 2014).

${ }^{15}$ El etnocentrismo de la educación intercultural lo encontramos en las realidades peruana y mexicana; respecto de esta última, Barriga señala que la interculturalidad es "la panacea de los problemas educativos y sociales de los indomexicanos" (BARRIGA, 2008: 1230).
} 
de aspiraciones progresistas modernas y principalmente uni-nacionalistas, sino como la clave para el entendimiento dramático desde las diferencias; como la clave para gatillar el tan (des)esperado (des)encuentro con el otro. Un encuentro que nos obligue a no desviar el rostro frente a la mirada del otro, ni a ofrecer una mirada compasiva frente al miserable rostro del otro; sino a ver el enjuiciante rostro del otro que nos acosa por no haber cuidado de él; seguimos en este punto a Levinas (2000) y a Heidegger (2007).

En otras palabras, la educación bilingüe intercultural más que buscar hacer presente al otro, debe conseguir la interpelación sub-versiva del otro. Se trata, a partir de la EIB, de producir una doble mirada: hacia fuera y hacia dentro, pues el sistema educativo multicultural solo produce una mirada hacia fuera, hacia la reproducción de alteridades mudas. Como dice Etxceberría: "Si en el multiculturalismo la palabra clave es respeto, en la interculturalidad la palabra clave es diálogo" (en IBÁÑEZ et al., 2012: 229). Llegados a este punto, quisiera compartir algunas reflexiones que vengo trabajando sobre la sub-versión -sí, con guión intermedial entre el prefijo y el lexema (YANGALI VARGAS, 2014).

En la revisión etimológica hallamos que la subversión forma parte de una red de términos, todos asociados a la 'versión', y esta al 'verso', por lo que se expande en vocablos como universo, perverso, adverso, reverso, transversal, conversión, subversión, etc. El vínculo del verso con sus étimos latinos 'vers' y 'vert' nos llevó al verso como unidad mínima del poema, que en la lengua griega es indisociable de la medida y la linealidad del lenguaje; cosméticamente hablando, del lenguaje vestido.

En su acepción latina, el verso, a diferencia del sentido siempre proyectivo (lineal o sideral) que tiene en la lengua griega, siempre vuelve a su motivación primaria, a aquel magma creativo que le da origen y (re)proyección. Este retorno traza una repetición siempre (re)vestida.

No obstante, la repetición retórica se ha encargado de desnudar, de desvestir, al verso, siendo el punto cumbre de esta acción el denominado arte por el arte occidental, por lo que nos orientamos a buscar su potencialidad en otro terreno que no sea el poético, y nos dirigimos al campo de lo político, donde el verso, el de la modernidad, ha incrementado su sentido y significado, al adoptar de la jerga jurídica inglesa el versus, en cuyo seno lo hegemónico y antagónico están en tensión permanente.

En un conjunto de versos, las tensiones producen el (des)encuentro entre estos. Uno de ellos -el Verso o la Versión- tiende hacia la naturalización de 
su centralidad y hegemonía, alrededor de la cual giran los otros versos. Este uni-verso o uni-versión, al instalarse como significante hegemónico, vacía de sentido y significado a los demás versos (las otras versiones), a los que silencia mediante lógicas de homogenización y trascendencia. Les arrebata la posibilidad de construir horizontes de sentido; de ahí la necesaria restitución de lo "sub". En este punto seguimos a Laclau y Mouffe (2011).

Pese la hegemonía del Verso, los versos silenciados resisten; de ahí que emerjan en los modos subversivo, sub-versivo y sub( )versivo. Subversivo cuando solo se hacen presentes en el clamor del silenciado. Sub-versivo cuando confrontan abierta y declaradamente la representación "uni-versal" a la que no necesariamente desarticulan, no obstante perturban desde el disparate, la locura, el reclamo. Sub( )versivo cuando la tensión generada por la resistencia y confrontación es in-representable, antagonismo que solo puede resolverse en el cuerpo de quien lo vive o experimenta.

Los violentos sucesos finiseculares del Perú del siglo XX han dado lugar a una producción discursiva, a un querer decir algo sobre el fenómeno desde disciplinas académicas y artísticas. Algunos de estos decires están del lado del uni-verso, y otros de la sub-versión ${ }^{16}$. Las producciones discursivas abordan textualmente el fenómeno y lo hacen para que un público (lector, crítico u espectador) acceda y refigure el fenómeno. En este proceso de refiguración, como receptores, hemos analizado las lógicas sub-versivas de dichos discursos; es decir, si los tales antagonizan el uni-verso representacional hegemónico, o solo lo justifican, normalizan y naturalizan.

Para ejemplificar lo dicho, quiero analizar la propagación del video que produjo la caída del régimen Fujimori-Montesinos, para poder distinguir entre un discurso que viene del archivo oficial, es decir del uni-verso (pervertido, por cierto), del acto de sub-versión: la difusión del video en las calles. El último acto hace evidente que la acción subversiva no tiene por qué ser ilegal. El acto de subversión se da en los canales que la legalidad establece, en los formatos que el sistema permite, y como en el caso peruano, con los mismos objetos que el uni-verso democrático fujimontesinista produjo. Siguiendo a Burke (1956), diríamos que el acto de sub-versión está en la motivación utópica o ideológica con la que el sujeto se opone y tensiona al sistema representacional.

Cuando las motivaciones emplean los lenguajes para mostrarse, dejamos de hablar de subversión para pasar a hablar de sub-versión; es decir, de dos componentes de

\footnotetext{
${ }^{16}$ Ricoeur vincula al texto con lo que él llama discurso, "el querer decir que precede a la articulación de la escritura. Tal discurso equivale a la prefiguración, a un primer momento en que el material textual aún no es escritura" (glosado por ALCÁNTARA, 2010: 17).
} 
la estructura morfológica de dicha palabra. La morfología misma de la palabra no permite incorporar más de dos versos, de dos versiones, que en realidad pueden y llegan a ser mucho más de dos. La versión al verse precedida, según la sintaxis misma de la palabra, por el sub, está haciendo referencia a otra u otras versiones que mediante el guión (-) entran, al mismo tiempo, en una relación de atracción (el guión como puente) y de abierto rechazo u aversión. En este sentido, la subversión es el adversario de la uni-versión, del uni-verso.

A partir de lo afirmado, una sociedad como la peruana y una clase política como la que viene conduciendo la política educativa desde el Ministerio de Educación, que introduce la educación intercultural bilingüe, la introduce para controlar la inclusión de las marginalizadas comunidades indígenas, una opción decolonial la haría para provocar la chirriante inclusión de la epistemología sub-versiva indígena -no importa si se da en desigualdad de condiciones-, entre todas las instituciones de educación básica y a nivel nacional.

Fuenzalida habla de una decisión política curricular a la que apelamos:

Concebir el currículum como un sistema estratégico en el que se puede poner en tensión las lógicas de poder. Pero también el currículum constituye un entramado por el que pueden ingresar significaciones ideológicas y construcciones culturales para asegurar su legitimación epistemológica (FUENZALIDA RODRÍGUEZ, 2014: 12).

Toda vez que la curricularización de la lengua originaria no cuenta con las ventajas competitivas con las que cuentan la enseñanza de la lengua española y, como es obvio, la de las lenguas extranjeras (la inglesa principalmente), en cuanto a institucionalidad, metodologías, medios, materiales y recursos, la lengua otra tiene que tener el respaldo emancipador de un cuerpo docente crítico. Y para ello se le tiene que dar voz a los representantes de la lengua otra al interior de los centros educativos no ejecutores de EIB. De este modo, el actor local indígena se hace parte activa del sistema educativo, y no solo la excusa tecnocrática ${ }^{17}$ para procurar su inclusión. La participación activa le exige al actor local asumir el desafío de transculturizar los saberes occidentales en la formulación de metodologías, medios y materiales y transformación de sus saberes locales en contenidos curriculares ${ }^{18}$.

\footnotetext{
${ }^{17}$ Calificada como etnoburocrática por Boccara (citado por POZO MENARES, 2014).

${ }^{18}$ Como nos lo recuerda Durin (2007), al hablar del proceso histórico de la asunción de la educación intercultural bilingüe por parte del estado mexicano: no se trata de buscar precisiones terminológicas para definir el fenómeno, sino de subrayar su carácter pedagógico.
} 
Pozo Menares critica la legislación chilena que alienta la inclusión de la lengua indígena en centros educativos que quieran favorecer la interculturalidad ${ }^{19}$; pues a su juicio desfavorece la transversalización de los contenidos indígenas en todas las asignaturas ${ }^{20}$. La escuela, más aún la intercultural, nunca puede ser neutral; siempre tiene la responsabilidad, expresa o no, de manifestar su compromiso, ya sea con los paradigmas ideológicos dominantes o con las actitudes de resistencia. $\mathrm{O}$ es subversiva o es sub-versiva. Fuenzalida Rodríguez destaca el efecto de la educación intercultural bilingüe:

Epistémicamente moderniza la escuela y los procesos de enseñanza-aprendizaje y, por otro lado, desde la escuela (EIB) se refuerza el proceso de valorización y revitalización de los saberes mapuche (para el caso chileno), que vertebran dos procesos: el de reetnización y el de resistencia epistémica. Todo ello posibilita la emergencia, con renovado ímpetu, de aquellos saberes ocultos que han estado largamente escondidos, invisibilizados, extintos, disueltos, prohibidos y desaparecidos (FUENZALIDARODRÍGUEZ, 2014: 12).

En otras palabras, la EIB favorece "[la] reaparición de tradiciones, cosmologías y de cosmovisiones" (FUENZALIDA RODRÍGUEZ, 2014: 12). Reaparición de lo que nosotros calificamos de sub-versiones. El problema con Fuenzalida es pensar el fenómeno educativo intercultural desde la sociedad mapuche, es decir desde los subalternos, y no desde y para los no mapuches, desde y para los colonizadores.

En ese sentido, cabe resumir que no basta con incorporar al currículo los saberes locales. La demanda es mayor y exige una apuesta mayor: saltar la valla de lo étnico sin perder de vista lo ya recorrido por la historia.

\section{Segunda apuesta: repensar la interculturalidad en territorios no solo étnicos}

Pozo explica, desde el ámbito mapuche chileno, el impacto de la educación intercultural bilingüe como,

[...] intervención e investigación de los pueblos indígenas que forma parte de una estrategia neocolonialista para continuar un sistema de

\footnotetext{
${ }^{19}$ Fuenzalida Rodríguez (2014: 2) dice que la legislación chilena alienta el "desarrollo de la EIB como un dispositivo que asegure la formación de los educandos indígenas para su desenvolvimiento en ambas sociedades.", vale decir como un mecanismo que asegura la integración del indígena al proyecto nacional chileno.

${ }^{20}$ Otra experiencia de legislación de EIB para todos, es la mexicana (DURIN, 2007).
} 
dominación y manipulación de aquellas personas que - a como dé lugar - deben integrarse al modelo occidental de civilización (POZO MENARES, 2014: 2).

Así visualizada la EIB Pozo, cuando sugiere la intervención de la comunidad mapuche con y desde su lengua en la construcción del modelo educativo intercultural: "De nada sirve que la EIB esté pensada sólo para los contextos de alta densidad indígena, ya que solo aumentaría los conflictos y discriminaciones" (POZO MENARES, 2014: 6). Eso lleva a Pozo a pensar la EIB circunscrita al coto de colegios EIB y proyectarla a los centros educativos de baja densidad indígena, esto es, a los habitados por los colonos como nosotros lo proponemos.

Muñoz Sedano, citado por Fuenzalida Rodríguez (2014: 4), señala la existencia de tres concepciones ideológicas que orientan la atención e inclusión de los grupos culturalmente diversos:

a) Concepciones orientadas a la afirmación hegemónica de la cultura del país de acogida. En estas concepciones se proponen lógicas asimilacionistas, compensatorias y segregacionistas. b) Concepciones orientadas al reconocimiento de la pluralidad de culturas en aspectos globales o parciales dentro del Estado-nación. En esta concepción se proponen lógicas multiculturales y de pluralismo cultura ${ }^{21}$. c) Concepciones orientadas hacia una sociedad intercultural basada en la simetría cultural. En estas últimas se contemplan políticas de reconocimiento de derechos a la diferencia hasta la refundación de los Estados-nación.

Quisiéramos señalar que nuestro proyecto, aunque por la clasificación hecha por Sedano parezca ser una concepción multiculturalista, no lo es. Todo lo contrario, ya que constituye un profundo análisis de la interculturalidad y su pretendido ideologema de "simetría cultural". Walsh, citada por Fuenzalida Rodríuez (2014), plantea tres perspectivas de la interculturalidad:

a) La interculturalidad relacional, en la que se reconoce la existencia, el contacto y el intercambio entre dos o más culturas; relaciones que se pueden dar en condiciones de simetría o desigualdad. Esta lógica, según Walsh, tiende a invisibilizar el

${ }^{21}$ Ferrão Candau propone tres perspectivas del multiculturalismo: el asimilacionista, el diferencialista o monocultural y el interactivo. Este último, según Ferrão, también puede ser llamado intercultural (FERRÃO CANDAU, 2014: 37). 
conflicto, la dominación y la colonialidad que se sustenta en relaciones de poder subordinantes.

b) La interculturalidad funcional, en la que se plantean metas de inclusión de la diversidad y diferencia en la perspectiva de promover el diálogo, la tolerancia y la convivencia. Las lógicas que sustentan esta concepción no ponen en tensión las reglas del juego, por lo que es compatible con la lógica del modelo neo-liberal. Walsh señala que en ella se reconoce "[...] la nueva lógica multicultural del capitalismo global" (en FUENZALIDA RODRÍGUEZ, 2014: 4).

c) La interculturalidad crítica, que no radica en el abordaje de la diversidad o diferencia como problema, sino en las lógicas y estructura del sistema-mundo moderno / colonial / racial; es decir en el " [...] reconocimiento de que la diferencia se construye dentro de una estructura y matriz colonial de poder racializado y jerarquizado, con los blancos y blanqueados en la cima y los pueblos indígenas y afrodescendientes en los peldaños inferiores" (FUENZALIDA RODRÍGUEZ, 2014: 4).

Compartimos con Ibáñez la concepción de la diversidad no como "una amenaza a la legítima aspiración de construcción de identidades colectivas, sino más bien una oportunidad para que en esa construcción tengan presencia importante y efectiva los valores democráticos de respeto por el otro, solidaridad y responsabilidad ciudadana” (Ibáñez et al., 2012: 235).

Esta postura lleva a Ibáñez-Salgado a entender la diversidad como "la consecuencia de modos distintos de construir significados que d[e]n lugar a una visión de mundo diversa en algunos o en muchos sentidos, no mejor o peor sino sólo diferente [...]" (IBÁÑEZ et al., 2012: 217). Desde esta perspectiva, el propósito de la educación intercultural bilingüe tendría que ser el de construir significados compartidos. Nos sumamos a esta perspectiva, entendiendo que compartir no necesariamente es aceptar, y menos, tolerar, una vez que entendemos el acto de compartir como aquel acto que nos lleva a la mesa de debate donde compartimos el mismo desayuno y aún el mismo pan, pero conservando el justo gusto por lo deglutido. Es decir, insistimos en nuestro proyecto por buscar la decolonialidad, no solo de la población blanqueda sino de la misma población blanqueante, en términos de Fanon (1952).

Geoculturalmente tenemos que hablar de una educación intercultural urbana, sin dejar de pensar y atender la interculturalidad rural o comunal. Pensarla, no 
porque en algunas escuelas, institutos y universidades se tengan niños o jóvenes indígenas o inmigrantes extranjeros, sino porque la EIB responde a la conformación heterogénea de nuestra sociedad.

Sobre la experiencia de la interculturalidad en la urbe, los trabajos de Barriga (2008) y Durín (2007) son ilustrativos. No obstante, en ambos casos se trata de la aplicación del programa interculturalidad circunscrito a los niños indígenas. Esto quiere decir que aunque el indígena migre a la ciudad en busca de un entorno educativo diferente, la interculturalidad lo alcanza para (alcan)lazarlo nuevamente. Esta perspectiva trata, insistimos, de pensar la interculturalidad como lazo natural de lo indígena, cuando de lo que se trata es de pensarla de modo diferente, como lo hace Virginia Molina cuando plantea que: "Para lograr que los niños y jóvenes indígenas desarrollen una identidad positiva respecto de su diferencia cultural, hay que modificar como es percibida por los no indígenas: es preciso quebrantar el racismo practicado hacia los indígenas" (citada por DURIN, 2007: 67).

La educación bilingüe intercultural del indígena en la ciudad lo invita/reta a afirmarse en su identidad. Muchos de ellos se delatan durante una clase de lengua nativa, al evidenciar su conocimiento de la lengua otra. Como lo precisa Durin en la experiencia mexicana urbana de la enseñanza bilingüe, la EIB exige que el niño indígena se afirme tomando en cuenta que: "la curiosidad de sus compañeros [no nativos], es un gran aliado" (DURIN, 2007: 87). Durin destaca el rol preponderante del maestro bilingüe, cuya presencia en la escuela "repercute de manera positiva en la formación del autoconcepto del educando indígena y en la revaloración positiva de su ascendencia indígena, además de que fortalece su autoestima y actúa a favor de la revitalización lingüística" (DURIN, 2007: 87) ${ }^{22}$.

Tomando en consideración la ubicación de lo político dentro de lo ético, la interculturalidad debiera abrirse, como lo propone Pedro Rojas, a la inclusión de los otros discursos contrahegemónicos: los contraculturales. Esto implicaría, según Rojas, superar la concepción que tenemos de lo contracultural como un discurso que solo ofrece una respuesta/negación. Para ello es necesario aproximar la definición política de la interculturalidad a un proyecto decolonial: poner en escena "lógicas, prácticas y modos culturales diversos de pensar, actuar y vivir" (Catherine Walsh, citada por ROJAS, 2014: 127). Esta definición funciona como un integrado cajón de sastre de todo lo contra hegemónico.

22 Los reportes de la EIB urbana mexicana son alentadores: "La lengua indígena, al entrar por la puerta grande en la escuela pública en boca de un maestro, genera un cambio profundo: esta se vuelve riqueza en vez de un problema que habría que solucionar" (DURIN, 2007: 87). 
Rojas (2014: 128) nos ofrece una tendencia de la interculturalidad: "una suerte de traslape entre lo étnico y lo cultural, que clausura la posibilidad de alteridades que encuentran su sustento más allá de lo étnico", transformando de este modo la interculturalidad en un mecanismo cerrado a lo étnico que "oblitera la posibilidad de incluir en el proyecto político otras culturas". Esto constituye un coto en el que lo étnico adquiere una mayor jerarquía cuando se trata de hablar de identidades y procesos de inclusión política, social y cultural. En este punto, las identidades (sub-versivas) sexuales o de género son "una especie de clase media" (ROJAS, 2014: 152); y las otras identidades, igualmente sub-versivas, como las subculturas o tribus urbanas, "el lumpen de esa escala" (ROJAS, 2014: 152).

\subsection{Testaruda apuesta: imponer el aprendizaje de lengua nativa desde lo político-jurídico, sea esta regional o local, para pensar desde la sufrida diferencia}

Estermann (2014) observa de manera crítica la influencia de la incorporación de conceptos como colonialidad, descolonización e interculturalidad en países que los han incorporado a sus políticas de Estado, principalmente en sus políticas educativas, como Bolivia y Ecuador. Podría tratarse de un "secuestro -dice Estermann (2014: 2)- etnocéntrico, posmoderno y un tanto romántico de una herramienta de interpretación sociopolítica y cultural". No obstante, Estermann observa una correspondencia dialéctica entre ambos, descolonización e interculturalidad, donde,

[...] el discurso de la 'interculturalidad' -al menos en el contexto latinoamericano- sin una reflexión crítica sobre el proceso de 'descolonización' queda en lo meramente intencional e interpersonal, pero también al revés: un discurso político y educativo de la 'descolonización' no llega al fondo de la problemática, si no toma en consideración un debate sobre los alcances y limitaciones de un diálogo intercultural (ESTERMANN, 2014: 2).

Estermann (2014) precisa que hablar de la interculturalidad a secas se define como un wishful thinking (pensamiento deseoso), mas no como un proyecto bien pensado. De modo parecido, Ibáñez (2012: 217) habla de una "visión de interculturalidad predominante" que la ancla "en una lógica tradicional, positivista, que se resiste a ser modificada"; de ahí la necesidad de aventurarnos a una propuesta de imposición del aprendizaje de la lengua otra entre los sujetos colonizantes, que modifique desde la decisión jurídico-política la concepción pasiva, exótica y turística de la interculturalidad. 
Creemos que es posible pensar la (des)articulación y apertura del discurso intercultural si lo pensamos desde el potencial sub-versivo de las identidades diferenciadas, y no desde la sujeción a lo homogéneo. Dar pase a la(s) subversión(es) tiene que ver con lo que el discurso decolonial llama visibilización de "los otros puntos de vista" (ROJAS, 2014: 146).

Pensar la educación desde la diferencia es pensarla desde la anormalidad, pues la modernidad pensó la educación como una tecnología homogeneizante (ESCARBAJAL, 2014). La educación bilingüe intercultural no puede pensarse solo desde lo instrumental, sino desde lo ético, desde lo sensiblemente humano, desde el reconocimiento de nuestra praxis colonizadora, desterritorializadora y discriminatoria, así como desde nuestra migrancia geocultural ${ }^{23}$.

Hablamos de algún modo de pensar la interculturalidad de segunda generación (señalada así por Escarbajal) que se caracteriza por afrontar los desafíos de la diversidad, la inmigración y la segregación, es decir, los desafíos nomádicos y no estacionarios. Pensar la educación intercultural desde la diferencia desigual implica no pensar la educación como asimilación sociocultural o como un acto de resistencia multiculturalista, sino como una pretensión de relación donde lo sub-versivo tiene lugar. No se trata de encajar en el sistema, sino de re-cognocser al otro. Esto es, en primer lugar, de procurar entablar un diálogo que en razón de estereotipos culturales se ha truncado; en segundo lugar, de hacerlo desde la inestabilidad e insuficiencia del conocer qué me lleva a no aceptar, ni justificar cual autómata; sino desde la aceptación de mi ser autónomo. En tercer lugar, de dialogar, siguiendo a Butler (2006), desde la comprensión de nuestro ser ontológicamente precario.

No se debe buscar, como lo sugieren Ibañez (2012), Pozo Menares (2014), Rincón Murcia (2007), Rojas (2014) la igualdad de condiciones para dialogar; simplemente se tiene que buscar el diálogo ${ }^{24}$. Pozo Menares (2014: 4) critica a la sociedad dominante que solo busca imponer y no aprender, y sugiere que el diálogo se dé en un ámbito de aprendizaje mutuo donde "las sociedades en contacto aprendan y conozcan sus respectivas cosmovisiones, tomando como referencia sus propios idiomas sin necesidad explícita de traducir". Esto implica paridad en el debate, que a nuestro juicio, constituye la principal debilidad de la retórica decolonial.

\footnotetext{
${ }^{23}$ Sobre la eficacia de la interculturalidad como modelo educativo en sociedades con altas tasas de inmigrantes, véase la experiencia europea (BEDMAR (2012), IGLESIAS (2014) y otros), en la que se entende la interculturalidad como medio de integración y de reconocimiento cultural.

${ }^{24}$ Ibáñez (2012: 226) propone la interculturalidad como un enfoque que "debiera optimizar las condiciones de equidad, promoviendo un modo dialógico de relaciones al interior de la sociedad, con el fin de lograr la participación real de los distintos sectores que la conforman".
} 
Cito como ejemplo de esta retórica, la concepción política de la interculturalidad como respuesta al proyecto multicultural, precisado por Catherine Walsh:

$\mathrm{Su}$ proyecto no es simplemente reconocer, tolerar o incorporar lo diferente dentro de la matriz y estructuras establecidas. Por el contrario es implosionar -desde la diferencia- en las estructuras coloniales del poder como reto, propuesta, proceso y proyecto; es re-conceptualizar y re-fundar estructuras sociales, epistémicas y de existencias que ponen en escena y en relación equitativa lógicas, prácticas y modos culturales diversos modos de pensar, actuar y vivir (En ROJAS, 2014: 127; resaltado nuestro).

Consensuamos con las ideas que Walsh propone en la primera parte de la definición; no obstante, tenemos que disentir frente a la última. Esto es, ante el (des)contexto de la implosión: la relación equitativa, puesto que la decolonialidad está pensada desde el colonizado como categoría social, y no desde la relación humana de dominio (colonización), en la que también es involucrado el colonizador.

Situarlos en un entorno neocolonial (o colonial posmo) como el amazónico peruano, donde conviven colonos que emigraron de la costa (criollos) y sierra (cholos), donde los colonos están signados por una historia igualmente desterritorializadora como la de los, ahora, colonizados amazónicos, nos permite figurar esta relación dicotómica de concreta disparidad que al mismo tiempo es heterogéneamente discriminatoria y marginalizadora, y simultáneamente homogeneizada por sentimientos de identidad territorial local. El territorio los une, a unos para la resistencia de su posesión originaria, y a los otros para justificar el haber echado raíces en tierras ajenas, que creen y legitiman como suyas.

En otras palabras, pensar el dialogo desde la disparidad es buscar conservar la diferencia como un derecho, aunque este sea un derecho que nos sub-estime; sin embargo, justamente en esta sub-estimación radica la peligrosidad potencial de nuestras reacciones que invitan al oprimiente a buscar canales de diálogo. Es decir, un derecho que le da soporte jurídico a mi resistencia y no pretende la neutralización del potencial de mi acción sub-versiva; entiéndase la sub-versión tanto como la producción de versos o producción discursiva, como la participación en la gestación de $\operatorname{actos}^{25}$.

\footnotetext{
${ }^{25}$ El poder discursivo de la sub-versión se suma a revisiones de los hechos históricos como el sugerido por Stuart Hall, quien sostiene que en el mundo actual, las luchas por el poder son "crescentemente, simbólicas e discursivas" (en FERRÃO CANDAU, 2014: 35).
} 
Estermann (2014: 5) sostiene que el "discurso de la inclusión y del diálogo pueden invisibilizar estructuras de asimetría y hegemonía que son características de sociedades coloniales y no de pueblos en vía de emancipación y auto-determinación" También habla de la triada colonialista de la modernidad europea: "negación, asimilación e incorporación" (2014: 6). El último proceso, la incorporación de la población indígena, vendría a ser parte de un proceso igualmente colonizador. En Bolivia, como en Latinoamérica, este discurso de la incorporación tiene que ver con el discurso de mestizaje y el despegue económico de los aymara.

Discrepamos con Rojas (2014: 149) respecto de la percepción de lo "equitativo como lo utópico"; al contrario, lo equitativo es un denodado esfuerzo que viene desde motivaciones ideológicas contingentemente modernas, mientras que la utopía tiene que ver con la radicalidad del cuerpo hacedor de utopías por hacerse de un lugar que el terreno ideológico le niega. Un cuerpo que se niega a la reproducción homogeneizante y equitativa, que se afirma en su radical y repetitiva diferencia biológicamente u-tópica.

Compartimos, con Estermann (2014) que el diálogo intercultural debe cuestionar las asimetrías (incluida la de género). Este cuestionamiento no tiene por qué clausurar el dialogo, pues estos -diálogo y cuestionamiento- tienen validez no porque se resuelvan las asimetrías, sino porque favorecen el (des)entendimiento entre diferentes en el terreno de lo concreto, lo que no sucedería si se alentase el cierre al diálogo. En ese sentido, este diálogo concreto no tiene que estar ni ser el más allá de la discusión teórica (complejidad de la articulación entre descolonización e interculturalidad), como lo sugiere Estermann; al contrario, lo que hace el diálogo/debate es traer la teoría al más acá cotidiano, es vulgarizar la teoría para que prevalezca la sub-versión discursiva.

\section{A modo de conclusión o más allá de la focalización de la EIB}

Los programas sociales y económicos tienen que ser focalizados; los programas educativos y culturales, por su naturaleza formativa, no tienen que serlo, y deben buscar ser generalizables, tal como reza el proyecto: una educación intercultural para todos. De hecho, cuanto más generalizables, mayor será el impacto de los programas educativos. La EIB tiene que crear conciencia y cambio en los colonos excluidores y desterritorializadores, a quienes se les tiene que recordar su ignominioso pasado e involucrar en procesos de aprendizaje, sensibilidad y responsabilidad social histórica y política ${ }^{26}$.

\footnotetext{
${ }^{26}$ Utilizo el calificativo de excluidor que emplea Tortosa (citado por BEDNAR, 2002: 85) al hablar de las formas de luchas contra la exclusión, las que tienen que procurar el cambio de aquellos.
} 
La enseñanza de la lengua indígena tiene que imponerse como una piedra en el zapato del estudiante excluidor, así como él, aunque no de manera intencional sino naturalizada por su ubicación dominante, le impone al indígena el aprendizaje de su lengua. En ese sentido, la enseñanza de la lengua indígena entre la población no originaria tiene que tener el respaldo político de los principales agentes educativos, es decir, de los profesores, tanto colonos como nativos.

Un estereotipo de la educación intercultural vista como ajena atañe el prejuicio de su deficiencia ${ }^{27}$. Una escuela deficiente forma niños deficientes, por lo que el reto de los profesores de las lenguas indígenas es enorme: construir hacia el exterior el prestigio de su lengua. Y para ello el reto es mayor, pues la temporalidad oral de las lenguas originarias es reconocida y prestigiosa, mas su escritura siempre es un motivo incomodo, pues implica valerse de las grafías de la lengua dominante, y por ende, es un acto de traición disimulada. Sin embargo, ese es el reto: escribir la lengua, sistematizarla, curricularizarla. $\mathrm{Y}$ este reto también se extiende a la comunidad académica universitaria.

Nuestra perspectiva es respaldada por aquel enfoque de la interculturalidad que más que estar dirigida a las poblaciones indígenas, debe entenderse como el "eje estructurador del currículum nacional” (Ibáñez et al., 2012: 219). Esta perspectiva le permite a Ibáñez reclamar la incorporación de la interculturalidad en el currículo del profesorado toda vez que "la convivencia prolongada que caracteriza el rol docente tiene consecuencias en la formación humana de los niños, niñas y jóvenes y su mayor incidencia en los primeros años de escuela" (IBÁÑEZ et al., 2012: 234). La misma propuesta es alentada por el Programa Alianza Perú para la Educación Rural "Ruta del Sol” (2014), aunque a diferencia de Ibáñez, su mirada sigue centrándose en los grupos o comunidades étnicas. La educación bilingüe intercultural tiene que dejar de ser vista como una concesión gubernamental o estatal a lo diverso; de ahí la importancia de ligarla a un proyecto nacional decolonial, que nos lleve a pensarla como una demanda que nos permitiría superar nuestra mirada racista y excluyente.

En la perspectiva trazada a lo largo del artículo apostamos por una educación bilingüe intercultural que aliente el diálogo y el debate interpeladores del colono como sujeto desterritorializador $\mathrm{y}$, al mismo tiempo, que concientice la agitación del desposeído y marginal en el auto-reconocimiento. Además, que promueva un diálogo polifónico constructor de un aprender a convivir reivindicativo del valor

\footnotetext{
${ }^{27}$ Sobre la experiencia mexicana Durin sostiene: "Después de una centuria de indigenismo, las escuelas a las que asisten los indígenas se siguen caracterizando por sus deficiencias" (DURIN, 2007: 68).
} 
de la diferencia ${ }^{28}$. Un diálogo en la disparidad socio-cultural pero políticamente decolonialista de los sujetos concretos. Un diálogo/debate abierto al disenso en lo universal, pero abierto al consenso en lo particularmente precario y sub()versivo del ser humano: la vida.

${ }_{28}$ Desde una política lingüística, Pedro Rojas nos recuerda el sentido de la discusión: la polifonía (2014: 124). 


\title{
Paths of peruvian education in the XXI century: interculturalizing, decolonizing and subverting
}

\begin{abstract}
In this paper we approach the intercultural approach in education. We start from the analysis of one of the most important products produced since the Peruvian education system took the intercultural approach. From a decolonial perspective, we propose three paths we should take if we want the intercultural approach not to be a burden for the indigenous population and rather to constitute itself as an emancipatory project for all Peruvians: curricularizing local knowledge, rethinking interculturality not only for ethnic territories, and imposing the learning of native languages in not intercultural schools.
\end{abstract}

Keywords: Education. Intercultural. Decoloniality. Language. Territory.

\section{Cursos da educação peruana no século XXI: interculturalizar, descolonizar e subverter}

\section{Resumo}

Neste artigo abordamos o conceito da interculturalidade na educação. Começamos a fazê-lo a partir da análise de um dos produtos mais importantes produzidos desde que o sistema educativo peruano adotou a abordagem intercultural. A partir de uma perspectiva descolonizadora propomos três caminhos que devemos tomar, se queremos que a abordagem intercultural não seja exclusiva para a população indígena e se constitua num projeto emancipatório de todos os peruanos, a saber: curricularizar o conhecimento local; repensar o intercultural não apenas dos territórios étnicos e impor a aprendizagem de línguas nativas nas escolas não interculturais.

Palavras-chave: Educação. Descolonialidade. Intercultural. Língua. Território. 


\section{References}

AGAMBEN, G. Homo sacer: el poder soberano y la nuda vida. Valencia: Pre-Textos, 2006.

ALCÁNTARA, J. R. Textralidad: textualidad y teatralidad en México. México, DF: Universidad Iberoamericana, 2010.

BADIOU, A. La ética: ensayo sobre la conciencia del mal. México: Herde, 2004.

BARRIGA, R. Miradas a la interculturalidad: el caso de una escuela urbana con niños indígenas. Revista Mexicana de Investigación Educativa, v. 13, n. 39, p. 1229-54, oct./dic. 2008.

BEDNAR, M. La educación social contra la exclusión: la interculturalidad. Estudios sobre las Culturas Contemporáneas, v. 8, n. 16, p, 83-95, dic. 2002.

BURKE, K. Language as symbolic action: essays on life, literature, and method. California: University of California, 1956.

BUTLER, J. Vida precaria: el poder del duelo y la violencia. Buenos Aires: Paidós, 2006.

COMISIÓN DE LA VERDAD Y RECONCILIACIÓN NACIONAL - CVR. Informe final. Lima: CVR, 2003. Disponível em: <http://cverdad.org.pe/ ifinal/>. Acesso em: 15 mar. 2016

DURIN, S. ¿Una educación indígena intercultural para la ciudad? Frontera Norte, v. 19, n. 38, p. 63-91, jul./dic. 2007.

ESCARBAJAL, A. La educación intercultural en los centros educativos. Revista Electrónica Interuniversitaria de Formación del Profesorado, v. 17, n. 2, p. 29-43, 2014. http://doi.org/10.6018/reifop.17.2.197291

ESTERMANN, J. Colonialidad, descolonización e interculturalidad: apuntes desde la filosofía intercultural. Polis (Santiago), v. 13, n. 38, p. 2-15, ago. 2014. http://doi.org/10.4067/S0718-65682014000200016

FANON, F. Piel negra, máscaras blancas. Madrid: Akal, 1952.

FERRÃO CANDAU, V. M. F. Ser professor/a hoje: novos confrontos entre saberes, culturas e práticas. Educação (Porto Alegre), v. 37, n. 1, p. 33-41, 2014. http://doi.org/10.15448/1981-2582.2014.1.15003 
FLORES, A. Buscando un inca: identidad y utopía en los andes. La Habana: Casa de las América, 1986.

FUENZALIDA RODRÍGUEZ, P. Re-etnización y descolonización: resistencias epistémicas en el curriculum intercultural en la Región de Los Lagos-Chile. Polis, n. 38, p. 2-17, 2014. http://doi.org/10.4000/polis.10059

HEIDEGGER, M. El ser y el tiempo. México, DF: Fondo de Cultura Economica, 2007.

IBÁÑEZ, N. et al. La comprensión de la diversidad en interculturalidad y educación. Convergencia: Revista de Ciencias Sociales, v. 19, n. 59, p. 215-40, mayo-ago. 2012.

IGLESIAS, E. La formación en interculturalidad en la educación en el tiempo libre: necesidades y estrategias desde una perspectiva de competencias interculturales. Revista Electrónica Interuniversitaria de Formación del Profesorado, v.17, n. 2, p. 167-82, abr./jun. 2014. http://doi.org/10.6018/reifop.17.2.197511

INSTITUTO DE INVESTIGACIÓN LINGÜÍSTICA APLICADA - CILA. Investigación aplicada a la educación intercultural bilingüe: asháninka: territorio, historia y cosmovisión. Lima: Unicef, 2012a. . Investigación aplicada a la educación intercultural bilingüe: shipibo: territorio, historia y cosmovisión. Lima: Unicef, $2012 \mathrm{~b}$.

LACLAU, E.; MOUFFE, C. H. Hegemonía y estrategia socialista: hacia una radicalización de la democracia. Buenos Aires: Siglo XXI, 2011.

LEVINAS, E. La huella del otro. México, DF: Taurus, 2000.

MARIÁTEGUI, J. C. 7 ensayos de interpretación de la realidad peruana. Caracas: Fundación Biblioteca Ayacucho, 2007.

POZO MENARES, G. ¿Cómo descolonizar el saber? El problema del concepto de interculturalidad. Polis, n. 38, p. 2-13, 2014. http://doi.org/10.4000/polis.10099

REGAN, J. Perfil etnográfico de los asháninka. América Indígena, v. 53, n. 1-2, p. 33-43, 1993.

RINCÓN MURCIA, A. P. La interculturalidad como paideia: educar en y para las diferencias. Cuadernos de Filosofia Latinoamericana, v. 28, n. 97, p. 117-23, 2007. 
ROJAS, P. ¿Porqué estudiar los movimientos sociales hoy? Apuntes subterráneos para la interculturalidad más allá de lo étnico. Desafios, v. 26, n. 1, p. 121-69, 2014. http://doi.org/10.12804/desafios26.12014.04

RUTA DEL SOL - INTIQ ÑAM. Aportes a la construcción de una propuesta de formación de docentes en educación intercultural bilingüe. [Lima], 2014.

UBILLUZ, J. C.; HIBETT, A., VICH, V. Contra el sueño de los justos: la literatura peruana ante la violencia política. Lima: Instituto de Estudio Peruanos, 2009.

VARESE, S. La sal de los cerros (una aproximación al mundo campa). Lima: Retablo de Papel, 1973.

YANGALI VARGAS, J. L. Poesía y escena peruana contemporánea: Flor de María Ayala y María Teresa Zuñiga: o la sub-versión en tiempos de subversión. 2014. 312 f. Tesis doctoral - Universidad Iberoamericana, Ciudad de México, 2014.

ŽIŽEK, S. Los siete velos de la fantasía: el acoso de las fantasías. México, DF: Siglo XXI, 1999.

\section{Informações do autor}

Jorge Luis Yangali Vargas: Doutor em Letras Modernas por la Universidad Iberoamericana, Ciudad de México. Docente en la Facultad de Educación de la Universidad Nacional del Centro del Perú. Contato: jyangali@pucp.edu.pe 